\title{
Comparative study of different routes of hysterectomy
}

\author{
Singh B. ${ }^{1}$, Soni S. ${ }^{2}$ \\ ${ }^{1}$ Dr. Bharti Singh, Assistant Professor, Department of Obs \& Gynaecology, AIIMS, Bhopal, ${ }^{2}$ Dr Sona Soni, Assistant \\ Professor, Department of Obs \& Gynaecology, GMC, Bhopal (M.P.) India.
}

Corresponding Author: Dr. Sona Soni, Assistant Professor, Department of Obs \& Gynaecology, Gandhi Medical College, Bhopal (M.P.) India. E-mail: drbharti01@gmail.com

\begin{abstract}
Background: To compare the various routes of hysterectomy and find the most commonly performed hysterectomy type and the various complications associated with each. Methods: This prospective study was carried out in the department of Obstetrics and Gynaecology, N.S.C.B. medical College, Jabalpur during June 2007 to August 2008. A total of 174 cases included in the study. The women were divided into three groups depending on the surgical approach: the abdominal group consisted of women who underwent hysterectomy via a suprapubic or median incision; the laparoscopically assisted vaginal hysterectomy (LAVH) group consisted of women who underwent vaginal hysterectomy assisted by laparoscopic procedure (excluding uterine artery ligation) and vaginal hysterectomy. Results: The indications of hysterectomy differed among groups. Four main indications in the cases coming to medical college: Fibroid, DUB, Genital prolapse and PID. Prolapse was a more frequent indication for vaginal hysterectomies; however, abdominal hysterectomies or Laparoscopically assisted vaginal hysterectomies were used in 16 out of the 76 cases that involved only prolapse. Fibroids were more frequently an indication for abdominal or laparoscopic assisted vaginal hysterectomy. Conclusion: The vaginal route has significant advantages over LAVH and abdominal hysterectomy and should be the route of first choice. Hence there is a tremendous scope for improvement by careful preoperative assessment, meticulous surgical techniques and proper postoperative care in order to reduce the complication rate.
\end{abstract}

Keywords: Vaginal hysterectomy, Prolapse, Fibroid, Laproscopy

\section{Introduction}

Hysterectomy, a Simple concept yet a procedure that has various physical, psychological and emotional implications for the women that undergo the procedure for some, it means an end to catamenial pain and inconveniences; for others it represents an abrupt unwanted termination of the potential for spontaneous procreation [1].

Hysterectomy is one of the most common major operations in women, and it is therefore vital to make an evidence based decision to choose the appropriate technique of hysterectomy. For years the abdominal route remained the unquestioned route for a hysterectomy with the vaginal route being used in less than a fourth of the population, in the presence of uterovaginal prolapse, and in the absence of the possible need for oophorectomy. This persisted through the years in spite of evidence that was forth coming in favor of the vaginal route $[2,3,4]$.

Manuscript received: $11^{\text {th }}$ December 2018

Reviewed: $20^{\text {th }}$ December 2018

Author Corrected: $26^{\text {th }}$ December 2018

Accepted for Publication: $31^{\text {st }}$ December 2018
Once the decision has been made to proceed with hysterectomy, the physician must then decide whether the procedure will be performed abdominally, vaginally or with laparoscopic assistance. The route chosen should be the one that best accomplishes the procedure in a particular patient in question. The surgeon must also give consideration to surgical experience and expertise, as well as the patients disease process. How the gynecologist chooses the route of hysterectomy varies between surgeons. Absolute and relative contraindications for vaginal hysterectomy have been proposed [5].

It has been suggested that LAVH offers advantages over vaginal hysterectomy. One study randomized patients who were candidates for vaginal hysterectomy to either LAVH or standard vaginal hysterectomy. All procedures were performed on an outpatient basis, with patients included who had a uterine size up to 16 wks gestational size. Hysterectomy still incurs a notable complications rate, with one fourth to one half of women experiencing one or more complications. Pelvic surgery risks one easily understood, considering the anatomy and technical details. 
Opening the vaginal cuff contaminates the peritoneal cavity to some degree with the upper vaginal bacterial flora. The bowel, bladder and ureters and close to the lines of incision, clamping and suturing [6]. The present study entitled "Comparative study of different routes of hysterectomy" was undertaken to compare the various routes as well as the perioperative complications and outcome associated with each procedure.

\section{Materials and Methods}

Place \& Type of Study: The present study entitled "Comparative study of different routes of hysterectomy" was conducted in the department of Obstetrics and Gynaecology N.S.C.B. Medical College Jabalpur from June 2007 to Aug 2008. A total of 174 cases included in the study. This is an observation prospective study.

\section{Patients selection}

\section{Inclusion \& Exclusion criteria}

- All women with benign gynecological disorders and planned for hysterectomy irrespective of their age.

- Women who have undergone hysterectomy

- Women were excluded if their primary diagnosis were related to cancer or pregnancy.

- Women who had oophorectomies concurrently with hysterectomy were included.

Surgical Procedures: If other procedures were done concurrently with the hysterectomy like vaginal repairs, appendicectomy or cholecystectomies were included. All women received prophylactic antibiotics at the beginning of the operation.

\section{Original Research Article}

The women were divided into three groups depending on the surgical approach: the abdominal group consisted of women who underwent hysterectomy via a suprapubic or median incision; the laparoscopically assisted vaginal hysterectomy (LAVH) group consisted of women who underwent vaginal hysterectomy assisted by laparoscopic procedure (excluding uterine artery ligation) and vaginal hysterectomy. Laparoscopic conversion was defined as any laparotomy procedure performed for any reason in the vaginal and LAVH group. The indications of laparoconversion were recorded.

The indication of surgery, type of anaesthesia given and operative time in hours was noted. Intra and postoperative complications associated with each procedure were recorded. Also documentation regarding blood transfusion during surgery was done. Minor post op. complications like post op. spotting, fever, UTI, ileus and wound infection were noted and compared with each procedure. Time to recovery was also evaluated. Length of hospital stay associated with each route of hysterectomy was also compared. Mortality associated with any procedure was recorded.

Statistical Analysis- The data of the present study were fed into the computer and after its proper validation, checking for error, coding and decoding were compiled and analysed with the help of SPSS 11.5 software for windows. Appropriate univariate and bivariate analysis and ANOVA (analysis of variance) for more than two means were carried out using t-test were calculated and tested. All means are expressed as mean \pm standard deviation. The critical values for the significance of the results were considered at 0.05 levels.

\section{Results}

This prospective study was carried out in the department of Obstetrics and Gynaecology, N.S.C.B. medical College, There are 4 main indications encountered in the cases. Prolapes was mainly operated by vaginal route. 2 cases of DUB operated by vaginal route (non descent vaginal hysterectomy). Main indication for TAH was fibroid, DUB and PID. 2 cases of III ${ }^{0}$ descent and 11 cases of $\mathrm{II}^{0}$ descent were operated by TAH (prolapse with Adnexal mass and Tubo-ovarian mass) Indication for LAVH was fibroid, PID, DUB \& $\mathrm{II}^{0}$ descent. There is no well defined indication for LAVH in the study. In all three groups, maximum cases start ambulation on day 3 and 4.P $>0.05$ (not significant)

Table-1: Patients characteristics

\begin{tabular}{|c|c|c|c|c|c|}
\hline \multicolumn{2}{|c|}{ Group } & Gravida & Parity & BMI & Hb \\
\hline \multirow{3}{*}{ LAVH } & Mean & 4.22 & 4.22 & 19.89 & 9.22 \\
\cline { 2 - 6 } & Std. Deviation & .972 & .972 & 1.537 & .833 \\
\cline { 2 - 6 } & $\mathrm{N}$ & 9 & 9 & 9 & 9 \\
\hline \multirow{4}{*}{ TAH } & Mean & 3.81 & 3.64 & 20.51 & 9.03 \\
\cline { 2 - 6 } & Std. Deviation & 1.681 & 1.646 & 2.051 & 1.293 \\
\cline { 2 - 6 } & $\mathrm{N}$ & 102 & 102 & 102 & 102 \\
\hline Vaginal & Mean & 3.97 & 3.95 & 20.83 & 9.56 \\
\cline { 2 - 6 } & Std. Deviation & 1.616 & 1.621 & 2.446 & 63 \\
\cline { 2 - 6 } & $\mathrm{N}$ & 63 & 63 & 63 & 63 \\
\hline
\end{tabular}


Original Research Article

In the study, the mean age for TAH was 42 years, mean age for vaginal was 48 yrs, LAVH was 41 yrs. Maximum patients in the present study were gravida and para 3, 4, 5 and above. Mean parity in TAH was 3.64, in vaginal 3.95 and in LAVH 4.22.P value $>0.05$ (not significant) in this study one vaginal and six TAH cases were nulliparous. Maximum patients had BMI between 18.5 to 25. Mean BMI for TAH was 20.5, for vaginal 20.8 and for LAVH 19.8.P value $>0.05$ (not significant)

Table-2: Distribution of patients according to presenting complaints

\begin{tabular}{|l|c|c|c|}
\hline & TAH & VAGINAL & LAVH \\
\hline Menorrhagia, irregular menses & $37(36.3 \%)$ & $3(4.8 \%)$ & $2(22.2 \%)$ \\
\hline Mass in lower abdomen & $4(3.9 \%)$ & 0 & 0 \\
\hline Something coming out of Pvt. Parts & $10(9.8 \%)$ & $51(81 \%)$ & $1(11.1 \%)$ \\
\hline White discharge PV, pain in lower abdomens & $12(11.8 \%)$ & 0 & $1(11.1 \%)$ \\
\hline Post menopausal bleeding & $2(2 \%)$ & 0 & $1(11.1 \%)$ \\
\hline Mixed complaints & $37(36.5 \%)$ & $9(14.4 \%)$ & $4(44.4 \%)$ \\
\hline
\end{tabular}

In TAH maximum (36.3\%) cases had complaints of menorrhagia and irregular menses, $11.8 \%$ had white discharge PV and pain in abdomen, $9.8 \%$ complaints of something coming out of private parts. In vaginal $81 \%$ cases complaints of something coming out of private parts. In LAVH, $22.2 \%$ cases had menorrhagia, irregular menses, rest had mixed complaints

Table-3: Distribution of patients according to menstrual history

\begin{tabular}{|c|c|c|c|c|}
\hline \multirow{2}{*}{ MH } & \multicolumn{3}{|c|}{ GROUP } & \multirow{2}{*}{ Total } \\
\cline { 2 - 5 } & TAH & Vaginal & LAVH & 75 \\
\multirow{2}{*}{ Excessive flow } & 63 & 6 & 6 & $43.1 \%$ \\
\hline \multirow{2}{*}{ Menopausal } & $61.8 \%$ & $9.5 \%$ & $66.7 \%$ & 36 \\
& 6 & 40 & 0 & $20.7 \%$ \\
\hline \multirow{2}{*}{ Normal flow } & $5.9 \%$ & 27 & $3 \%$ & 63 \\
\hline Total & 33 & $42.9 \%$ & $33.3 \%$ & $36.2 \%$ \\
\hline
\end{tabular}

In $\mathrm{TAH}, 61.8 \%$ had menorrhagia and excessive menstrual flow, 32.4\% had normal flow and 5.9\% were menopausal. In vaginal $47.65 \%$ were menopausal, another $42.9 \%$ had normal flow. In LAVH, neither of the case was menopausal, $66.7 \%$ had excessive menses, $33.3 \%$ cases had normal flow.

Table- 4: Distribution of patients according to pelvic USG

\begin{tabular}{|l|c|c|c|c|}
\hline Pelvic USG & TAH & Vaginal & LAVH & Total \\
\hline \multirow{2}{*}{ Normal Study } & 49 & 62 & 6 & 117 \\
& $48.0 \%$ & $98.4 \%$ & $66.7 \%$ & $67.2 \%$ \\
\hline \multirow{2}{*}{ Adenomyosis } & 1 & 0 & 0 & 1 \\
& $1.0 \%$ & $.0 \%$ & $.0 \%$ & $.6 \%$ \\
\hline \multirow{2}{*}{ Cervical polyp } & 2 & 0 & $.0 \%$ & $1.1 \%$ \\
\hline \multirow{2}{*}{ Endometrial Hyperplasia } & $2.0 \%$ & $.0 \%$ & 0 & 5 \\
\hline \multirow{2}{*}{ Fibroid } & 4 & 1 & $.0 \%$ & $2.9 \%$ \\
\hline \multirow{2}{*}{ Pyometra } & $3.9 \%$ & $1.6 \%$ & 3 & 44 \\
& 41 & 0 & $33.3 \%$ & $25.3 \%$ \\
\hline \multirow{2}{*}{ Ovarian Cyst } & $40.2 \%$ & $.0 \%$ & $.0 \%$ & 2 \\
& 2 & 0 & 0 & $1.1 \%$ \\
\hline Uterine Descent & $2.0 \%$ & $.0 \%$ & $.0 \%$ & 2 \\
\hline Total & 2 & 0 & 0 & $1.1 \%$ \\
\hline
\end{tabular}


Original Research Article

In TAH, 48\% cases had normal study, 40.2\% had fibroid uterus, 3.9\% had Endometrial Hyperplasia, 2\% had Pyometra, another $2 \%$ had Ovarian Cyst. In vaginal, 98.4\% cases had normal study, only 1 case had Endometrial Hyperplasia. In LAVH, $66.7 \%$ cases had normal study, $33.3 \%$ had Fibroid uterus.

Table-5: Distribution of patients according to uterine size

\begin{tabular}{|l|c|c|c|c|}
\hline \multirow{2}{*}{ Uterine Size } & \multicolumn{2}{|c|}{ GROUP } & \multirow{2}{*}{ Total } \\
\cline { 2 - 5 } & TAH & Vaginal & LAVH & \\
\hline Normal Size & 49 & 61 & 7 & 117 \\
& $48.0 \%$ & $96.8 \%$ & $77.8 \%$ & $67.2 \%$ \\
\hline Bulky to 12 wks & 31 & 2 & 2 & 35 \\
& $30.4 \%$ & $3.2 \%$ & $22.2 \%$ & $20.1 \%$ \\
\hline $12-20$ wks & 13 & 0 & 0 & 13 \\
& $12.7 \%$ & $.0 \%$ & $.0 \%$ & $7.5 \%$ \\
\hline $20+$ wks & 9 & 0 & 0 & $5.2 \%$ \\
\hline
\end{tabular}

In TAH, Uterine size was normal in $48 \%$ cases, Bulky to $<12$ wks in $30.4 \%$ cases, $12-20$ wks in $12.7 \%$ cases and more than 20 wks in 8.85 cases. In vaginal, $96.8 \%$ cases had normal size uterus and 2 cases had Bulky to 12 wks uterus. LAVH, 77.8\% cases had normal size uterus and $22.2 \%$ had Bulky to 12 wks uterus.

1. $\mathrm{LAVH}$ v/s TAH $-\mathrm{P}<0.05$ (Highly significant)

2. $\mathrm{LAVH}$ v/s vaginal $\mathrm{P}>0.05$ (not significant)

3. TAH v/s vaginal $\mathrm{P}<0.001$ (very highly significant)

Table-6: Distribution of patients according to Uterine Mobility

\begin{tabular}{|c|c|c|c|c|}
\hline \multirow{2}{*}{ Uterine Mobility } & \multicolumn{3}{|c|}{ GROUP } & \multirow{2}{*}{ Total } \\
\cline { 2 - 5 } & TAH & Vaginal & LAVH & 168 \\
\hline Yes & 96 & 63 & 9 & $96.6 \%$ \\
\hline No & $94.1 \%$ & $100.0 \%$ & $100.0 \%$ & 6 \\
& 6 & 0 & 0 & $3.4 \%$ \\
\hline Total & $5.9 \%$ & $.0 \%$ & $.0 \%$ & $\mathbf{1 7 4}$ \\
\hline
\end{tabular}

Uterus was mobile in all cases of LAVH and vaginal, uterine mobility restricted in 6 cases of TAH. There are 4 main indications encountered in the cases. Prolapes was mainly operated by vaginal route.

2 cases of DUB were operated by vaginal route (nondescent vaginal hysterectomy). Main indication for TAH was fibroid, DUB and PID. 2 cases of III $^{0}$ descent and 11 cases of II $^{0}$ descent were operated by TAH (prolapse with Adnexal mass and Tuboovarian mass) Indication for LAVH was fibroid, PID, DUB \& $\mathrm{II}^{0}$ descent. There is no well defined indications for LAVH in the study. In all three groups, maximum cases start ambulation on day 3 and 4.P $>0.05$ (not significant).

Mean duration of hospital stay for TAH was 9.1 days $\pm 1.92 \mathrm{SD}$, and for vaginal was 8.62 days \pm 1.06 SD and for LAVH was 9 days $\pm 1.65 \mathrm{SD} . \mathrm{TAH}$ v/s vaginal $-\mathrm{P}<0.05$ (highly significant). LAVH v/s vaginal $-\mathrm{P}>0.05$ (not significant). LAVH v/s $\mathrm{TAH}-\mathrm{P}>0.05$ (not significant)

\section{Discussion}

Hysterectomy has long been regarded as an operation performed by "hyster-happy," mostly male, surgeons. The medical historian Roy Porter counted the rising tide of hysterectomies among manifestations of the "abuse of gynaecological surgery to control women" in the 19th century. Although campaigns against unnecessary hysterectomy have been vocal, this operation survived the

Obsgyne Review: Journal of Obstetrics and Gynecology feminist whirlwind of the mid to late 20th century and remains one of the most commonly performed operations in the world. The present study entitled "Comparative study of different routes of hysterectomy" was conducted in the department of Obstetrics and Gynecology NSCB Medical College, Jabalpur from June 2007 to August 2008. 
Present study entitled "comparative study of different routes of hysterectomy" was conducted in the department of obstetrics and Gynecology N.S.C.B. Medical College Jabalpur from June 2007 to Aug. 2008. A total 174 cases were included in the study. Hysterectomy was performed by abdominal route, vaginal route and LAVH in 102, 63 and 9 cases respectively.

Most of the cases in the study were from rural areas (as maximum cases in our medical college come from rural areas which comes under the Jabalpur division). Mean parity was $3.78 \pm 1.61 \mathrm{SD}$ and mean BMI was $20.59 \pm 2.1$ SD and did not differ between the three groups. Nulliparous patients were statistically more frequent in the TAH group as compared to vaginal and LAVH $(\mathrm{P}<0.05)$. There is no difference in the socioeconomic status between the three groups. ( $\mathrm{P}>0.05$, not significant). $53.3 \%$ at women were post- menopausal, of which $47.6 \%$ were from vaginal group (as prolapse is precipitated after menopause). Mean $\mathrm{Hb}$ level in the study was $9.23 \mathrm{gm} \% \pm$ 1.26 SD and did not differ between the three groups ( $\mathrm{P}>0.05$, not significant) $[5,6]$.

The indications of hysterectomy differed among groups. Four main indications in the cases coming to medical college: Fibroid, DUB, Genital prolapse and PID. Prolapse was a more frequent indication for vaginal hysterectomies; however, abdominal hysterectomies or Laparoscopically assisted vaginal hysterectomies were used in 16 out of the 76 cases that involved only prolapse. Fibroids were more frequently an indication for abdominal or laparoscopic assisted vaginal hysterectomy $[7,8]$.

About 2 of the DUB cases operated by vaginal route (non-descent vaginal hysterectomy). Uterine size differed among the groups. It was significantly higher in the abdominal group than the vaginal group $(\mathrm{P}<0.05)$ and the LAVH group $(\mathrm{P}<0.05)$. No significant difference in the uterine size was found between $\mathrm{LAVH}$ and the vaginal group. Uterus was mobile in all cases at vaginal and LAVH, mobility restricted in 6 cases of TAH $[9,10]$.

Co morbidity like anaemia, asthma and hypertension were more frequently associated with abdominal group. The frequencies of prior caesarean section and prior pelvic or bowel surgery differed among the groups. Patients operated on by vaginal route had no history of previous caesarean section. 5 cases of TAH had history of previous caesarean section. About 2 cases of vaginal and 1 case of abdominal had history of previous bowel surgery $[11,12]$. In the study abdominal route was more likely associated with other surgical indications. (One case had adnexal mass and one operated for gall bladder calculi along with

\section{Original Research Article}

hysterectomy and one had appendicectomy done along with hysterectomy). The mean operating time differed among the groups. It was significantly shorter in vaginal and abdominal group than in the LAVH group $(\mathrm{P}<0.05)$.

Intra and post- operative complications were significantly more frequent in the abdominal group as compared to vaginal and LAVH. 2 cases of TAH had significant haemorrhage from some major vessels. 1 case of TAH had ureteric injury. 1 case of vaginal and 1 case of LAVH had significant haemorrhage from some major vessel requiring laparoconversion. Laparoconversion prolongs the hospital stay and the recovery time. The rate of laparoconversion in the study was $12.7 \%$ overall and was higher with LAVH (11.2\%) as compared to vaginal hysterectomy $(1.6 \%)$. 2 cases of TAH had intraabdominal haemorrhage on post- op day 1 requiring reopening [13 -18].

$51 \%$ cases of TAH had blood transfusions which was significantly higher than vaginal and LAVH $(\mathrm{P}<0.05)$. As more anaemic patients are there in the TAH group. LAVH and vaginal group had early recovery than TAH group (early ambulation, taken full diet earlier, passed motion earlier). The incidence of post operative infection or fever and Ileus were higher after abdominal than after LAVH and vaginal. The incidence of post op spotting were higher after vaginal than abdominal and LAVH $(\mathrm{P}<0.05$, highly significant).

There was increased frequency of UTI after vaginal hysterectomy $(17.5 \%)$ as compared to abdominal (1\%) and LAVH (11.1\%). 2 cases of TAH and 1 case of vaginal in which laparotomy was done, reported wound infection.

Cost-efficiency of different routes could not derived as maximum patients were under Deen Dayal Yojna. Mean duration of hospital stay for abdominal group is more 9.17 days $\pm 1.9 \mathrm{SD}$ as compared to vaginal 8.62 days \pm 1.069 SD. Mean duration of hospital stay did not differed between LAVH and TAH in the study $[19,20]$.

\section{Conclusion}

There were 3 mortalities of cases of abdominal group. One death related to Intra-abdominal hemorrhage and one due to urinary tract injury. Another one died because of DIC and BT reaction. There was no mortality in LAVH and vaginal group. Study supports the view that, when possible, the vaginal route has significant advantages over LAVH and abdominal hysterectomy and should be the route of first choice. Hence there is a tremendous scope for improvement by careful pre operative assessment, meticulous surgical techniques and proper post operative care in order to reduce the complication rate. 
Contribution by different author during study process and manuscript preparation: Actively participated in the study and made valuable contributions in finding references, convincing and counseling the patients, recording data and interpreting it by statistical analysis.

This study add to existing knowledge: Study support the view that, when possible, the vaginal route has significant advantages over LAV Hand abdominal hysterectomy and should be the route of first choice. Hence there is a tremendous scope for improvement by careful pre operative assessment, meticulous surgical techniques and proper post operative care in order to reduce the complication rate.

\section{Funding: Nil, Conflict of interest: Nil \\ Permission from IRB: Yes}

\section{References}

1. Shirish S Sheth, Kurush P. paghdiwalla, Decision making for choice of Hysterectomy (Principles and practice of obstetrics and Gynecology for postgraduates), 374.

2. Thomas G. Stovall, Vaginal, Abdominal, Laparos copic- Assisted Hysterectomy Book of Gynecologic Surgery 403-407.

3. Thomas W. Mc Donald, Hysterectomy. Indications, types and alternatives, Book of Gynecology, 1024-1029.

4. Reich H, De caprio J, Mc Glynn F. Laparoscopic Hysterectomy. Gynecology Surgery1989; 213-226.

5. David-Montefiore E, Rouzier R, Chapron C, et al. Surgical routes and complications of hysterectomy for benign disorders: a prospective observational study in French university hospitals. Hum Reprod. 2007 Jan; 22(1):260-5. Epub 2006 Sep 1. DOI:10. 1093/ humrep/ del336

6. Kovac SR. Hysterectomy outcomes in patients with similar indications. Obstet Gynecol. 2000 Jun;95 (6 Pt 1):787-93.

7. Van Den Eden, Stephen K, Glasser Mark: Quality of life, health care utilization and costs among women undergoing hysterectomy in a manged care setting. American Journal of Obstetrics and Gynecology. 91-100, Jan 1998.

\section{Original Research Article}

8. Kang YP, Lee SN, Kang CG : Laparoscopically assisted vaginal hysterectomy : A review of 43 cases. Korean J. Obstetrics and Gynecology, 1998 : 2621-2624.

9. Michel Cosson, Malik Boukerrou, Eric Lambaudic : Hysterectomy for benign lesions : What is left for the abdominal route. Journal of Gynecology Surgery, Dec. 2001: 109-114.

10. Ronald $\mathrm{M}$,: What I have learned from performing vaginal hysterectomy. Medscape, Obstetrics and Gyneco. \& Women's health, 2003.

11. Malinowski A, Bobin L, Ma Clolak - Blewniewska G: Significance of laparoscopic assistance in vaginal hysterectomy. Jr. Article, Ginekol Pol 2005, 20-7.

12. Boukerrou $\mathrm{M}$, Lambaudie $\mathrm{E}$, Collinet $\mathrm{P}$, et al. A history of cesareans is a risk factor in vaginal hysterectomies. Acta Obstet Gynecol Scand. 2003 Dec; 82 (12):1135-9.

13. Councell RB, Thorp JM Jr, Sandridge DA, et al. Assessmentsof laparoscopic-assisted vaginal hysterectomy. J Am Assoc Gynecol Laparosc. 1994 Nov; 2 (1): 49-56.

14. Bronitsky C, Stuckey SJ. Complications of laparoscopic-assisted vaginal hysterectomy. J Am Assoc Gynecol Laparosc. 1995 May;2(3):345-7.

15. Obstetrics-Gynecology News, by Nacy Wals: Hysterectomy Guidelines often are not followed. 2000.

16. Edozien LC. Hysterectomy for benign conditions. BMJ. 2005 Jun 25;330(7506):1457-8. DOI:10.1136/ bmj. 330.7506 .1457

17. Mukherjee SN. Role of hysterectomy and its alternatives in benign uterine diseases. $\mathrm{J}$ Indian Med Assoc. 2008 Apr; 106(4):232-4, 236.

18. Kovac SR, Barhan S, Lister M, et al. Guidelines for the selection of the route of hysterectomy: application in a resident clinic population. Am J Obstet Gynecol. 2002 Dec; 187(6):1521-7.

19. Bobin L, Maciołek-Blewniewska G, Malinowski A. [Operating time of laparoscopically assisted vaginal hysterectomy (LAVH)--the causative factors and the course of the postoperative period]. Ginekol Pol. 2007 Mar; 78 (3):204-9.

\section{How to cite this article?}

Singh B., Soni S. Comparative study of different routes of hysterectomy. Obs Rev:J obstet Gynecol 2018;4(4):8994.doi:10.17511/joog.2018.104.04. 